Citation: M. Fernández-Aparicio, A. Cimmino, G. Soriano, M. Masi, S. Vilariño, A. Evidente (2021) Assessment of weed root extracts for allelopathic activity against Orobanche and Phelipanche species. Phytopathologia Mediterranea 60(3): 455-466. doi: 10.36253/ phyto-12917

Accepted: October 6, 2021

Published: December 30, 2021

Copyright:@2021 M. Fernández-Aparicio, A. Cimmino, G. Soriano, M. Masi, S. Vilariño, A. Evidente. This is an open access, peer-reviewed article published by Firenze University Press (http:// www.fupress.com/pm) and distributed under the terms of the Creative Commons Attribution License, which permits unrestricted use, distribution, and reproduction in any medium, provided the original author and source are credited.

Data Availability Statement: All relevant data are within the paper and its Supporting Information files.

Competing Interests: The Author(s) declare(s) no conflict of interest.

Editor: Maurizio Vurro, National Research Council, (CNR), Bari, Italy.
Research Papers

\section{Assessment of weed root extracts for allelopathic activity against Orobanche and Phelipanche species}

\author{
Mónica FERnÁndeZ-APARICIO ${ }^{1, *}$, Alessio CimMinO ${ }^{2}$, Gabriele \\ SORIANO $^{2}$, MARCO MASI $^{2}$, SusANA VILARIÑO ${ }^{3}$, ANTONIO EVIDENTE $^{2, \star}$ \\ ${ }^{1}$ Institute for Sustainable Agriculture-CSIC, Avda. Menéndez Pidal sn, 14004 Córdoba, \\ Spain \\ ${ }^{2}$ Department of Chemical Sciences, University of Naples Federico II, Complesso Universi- \\ tario Monte S. Angelo, Via Cintia, 80126 Naples, Italy \\ ${ }^{3}$ ALGOSUR S.A., Ctra Lebrija-Trebujena km 5.5, Lebrija - Sevilla, Spain \\ ${ }^{*}$ Corresponding author. E-mail: monica.fernandez@ias.csic.es; evidente@unina.it
}

Summary. Broomrapes (Orobanche and Phelipanche species) are holoparasitic weeds that infect roots of crop hosts from Asteraceae, Brassicaceae, Apiaceae, Fabaceae, and Solanaceae. The parasitic weeds are difficult to control selectively without crop damage once attached to their roots. Identification of natural compounds with herbicidal activity against pre-attached broomrape stages can provide control alternatives. With the aim to identify plant species with efficacy for broomrape control, organic and residual aqueous phase extracts from roots of seventeen weed species common in south Spanish broomrape-infested fields were assessed as potential inducers of suicidal broomrape germination and as inhibitors of broomrape radicle growth. Assessments were carried out in vitro using seeds and seedlings of four noxious broomrape species, Orobanche crenata Forsk., Orobanche cumana Wallr., Orobanche minor Sm. and Phelipanche ramosa (L.) Pomel. While root extracts from all the weed species did not induce suicidal germination on $O$. crenata seeds, most of the extracts induced germination of $P$. ramosa except for those obtained from Amaranthus albus L., Amaranthus retroflexus L. and Convolvulus arvensis L. Moderate levels of germination activity were induced in $O$. cumana and $O$. minor seeds by some of the root extracts tested, with strongest induction obtained from Heliotropium europaeum L. on O. cumana seeds, and from Silybum marianum (L.) Gaertn. on O. minor seeds. For root extract inhibition of broomrape radicles, the extract from $C$. arvensis roots strongly inhibited radicles of all the broomrape species. While extracts from the other weed species induced low or negligible inhibition of $O$. cumana and $O$. crenata radicle growth, many inhibited $P$. ramosa and O. minor radicles. Exceptions were root extracts from Datura stramonium L., Heliotropium europaeum L., Malva sylvestris L., Solanum nigrum L. and Urtica dioica L., which did not inhibit $P$. ramosa radicles, and those from A. retroflexus, Datura stramonium L., Malva sylvestris L., Portulaca oleracea L. and S. nigrum, which did not inhibit O. minor radicles. Among the active organic extracts assessed, those showing promising chemical profiles were selected for future studies to characterize natural compounds with potential herbicidal activity on early stages of broomrape growth.

Keywords. Allelopathy, broomrape weeds, parasitic weed management, sustainable crop protection. 


\section{INTRODUCTION}

Among all pests, weeds have the largest economic impact in agriculture (Pimentel et al., 2005), and among weeds, the holoparasitic broomrapes (Orobanche and Phelipanche species) are particularly noxious, since they compete with crops for nutrients by invading their roots for nutrient extraction. Broomrapes have expanded in importance, becoming threats to food security (Parker, 2009).

For successful crop plant infections, broomrape germination is inhibited until detection of host roots through root-derived germination stimulants (Lechat et al., 2012; Fernández-Aparicio et al., 2009). From each germinated broomrape seed a short radicle emerges that grows towards the host root and then develops a multicellular haustorium. This attaches and penetrates the host root, and forms connections with the host vascular system to withdraw water and nutrients (Riopel and Timko 1995; Joel, 2013). Nutrient withdrawal through haustorial connections results in severe reductions of crop yields (Fernández-Aparicio et al., 2016). Because of synchronization of host-parasite life cycles and the intimate haustorial attachments, application of methods that kill the parasitic weeds without damaging host crop are not easy, so parasitic weeds are amongst the most difficult weeds to control (Fernández-Aparicio et al., 2020).

The most used broomrape control methods are based on systemic herbicides commonly employed for the management other weeds, including inhibitors of aromatic synthesis (glyphosate) or branched-chain amino acid synthesis (imidazolinones and sulfonylureas) (Eizenberg et al., 2013). However, sustainability of herbicide control methods is threatened by the high capacity of weeds to develop resistance coupled with decline in authorized herbicides and lack of discovery of new herbicide mechanisms of action (Duke, 2012; Westwood et al., 2018; Heap, 2021). The mechanisms that broomrapes use to infect crops, i.e. host-induced germination and radicle growth towards host roots for haustorium attachment, can be targeted by natural products which stimulate suicidal broomrape germination in the absence of host plants (Zwanenburg et al., 2016), or which inhibit broomrape radicle growth towards host roots (Cimmino et al., 2014). Development of control of parasitic plants based on natural substances could increase sustainability and efficacy of weed management, and potentially reduce environmental impacts and human health effects.

Allelochemicals are biologically active compounds released from donor plants with allelopathic potential against target plants. The International Allelopathy Society defined allelopathy as any process involving sec- ondary metabolites produced by plants, algae, bacteria or fungi that influence the growth and development of agricultural and biological systems (International Allelopathy Society, 1996). Many natural compounds have potential as novel agrochemicals (Dayan and Duke, 2014), but only a few microbial or plant metabolites have been screened for their herbicidal activity (Westwood et al., 2018). From screening of microbial or plant toxins, allelochemicals with activity against parasitic weeds have been discovered, which act on seed germination and radicle development (Evidente et al., 2009; Vurro et al., 2009; Evidente et al., 2010; 2011; Cimmino et al., 2014; Cimmino et al., 2015).

The Lithica poem (circa 400 B.C.) noted that "All the pests that out of earth arise, the earth itself the antidote supplies" (Ibn et al., 1781). This inspired the present study to consider the use of root extracts from autotrophic weeds as sources of metabolites in crop rhizosphere to control parasitic weeds. This paper reports the allelopathic activity of root extracts from 17 dicotyledonous weed species that usually thrive on broomrapeinfested fields in the south of Spain. Extract activity was assessed for effects on germination and radicle growth of Orobanche crenata Forsk., Orobanche cumana Wallr., Orobanche minor Sm., and Phelipanche ramosa (L.) Pomel, which are four of the most noxious broomrape weeds affecting crops in many parts of the world (Parker, 2013).

\section{MATERIALS AND METHODS}

\section{Plant material and growth conditions}

Seeds of seventeen weed species (Table 1) were collected during the season of 2016-2017 from a buckwheat field at the Institute for Sustainable Agriculture (IASCSIC), Alameda del Obispo Research Center (Córdoba, southern Spain, coordinates 37.856 N, 4.806 W, datum WGS84). The weed species collected frequently occur in southern Spain agricultural fields where O. crenata and O. cumana also thrive in. In spring 2020, the collected weed seeds were surface sterilized by immersion in $0.5 \%$ (w/v) $\mathrm{NaOCl}$ and $0.02 \%$ (v/v) Tween 20 for $5 \mathrm{~min}$, rinsed thoroughly with sterile distilled water, and dried in a laminar airflow cabinet. The seeds were then sown into pots each containing $1 \mathrm{~L}$ of $1: 1$ sand and peat, which were maintained in a greenhouse for $40 \mathrm{~d}$ with day/night regime of $23 / 20^{\circ} \mathrm{C}, 16 / 8 \mathrm{~h}$ light/dark.

Because broomrapes infect host crop roots and mostly develop underground, extracts from weed roots were used, aiming to identify potential allelopathic signals acting in plant rhizospheres. For collection of roots, 
Table 1. Weed species investigated for root allelopathic activity against four broomrape species, and mean yields of organic extracts from the $\mathrm{CH}_{2} \mathrm{Cl}_{2}$ extractions from dry roots.

\begin{tabular}{|c|c|c|c|}
\hline Plant family & Plant species & EPPO Code * & $\begin{array}{c}\text { Weight in mg of } \mathrm{CH}_{2} \mathrm{Cl}_{2} \\
\text { organic extract. } \\
\text { (\% of root dry weight) }\end{array}$ \\
\hline \multicolumn{4}{|c|}{ Weed species donor of the allelopathic activity } \\
\hline Amaranthaceae & Amaranthus albus & EPPO:AMAAL & $14.40(0.23)$ \\
\hline Amaranthaceae & Amaranthus retroflexus & EPPO:AMARE & $19.93(0.32)$ \\
\hline Asteraceae & Conyza bonariensis & EPPO:ERIBO & $23.60(0.39)$ \\
\hline Asteraceae & Silybum marianum & EPPO:SLYMA & $16.67(0.28)$ \\
\hline Boraginaceae & Heliotropium europaeum & EPPO:HEOEU & $21.24(0.34)$ \\
\hline Brassicaceae & Capsella bursa-pastoris & EPPO:СAPBP & $22.13(0.78)$ \\
\hline Brassicaceae & Diplotaxis erucoides & EPPO:DIPER & $29.62(0.49)$ \\
\hline Brassicaceae & Diplotaxis virgata & EPPO:DIPVG & $41.93(0.70)$ \\
\hline Convolvulaceae & Convolvulus arvensis & EPPO:CONAR & $77.42(1.28)$ \\
\hline Malvaceae & Malva sylvestris & EPPO:MALSI & $36.24(0.74)$ \\
\hline Papaveraceae & Fumaria officinalis & EPPO:FUMOF & $39.02(1.85)$ \\
\hline Polygonaceae & Polygonum aviculare & EPPO:POLAV & $29.77(0.49)$ \\
\hline Portulacaceae & Portulaca oleracea & EPPO:POROL & $25.53(0.36))$ \\
\hline Solanaceae & Datura stramonium & EPPO:DATST & $18.64(0.31)$ \\
\hline Solanaceae & Solanum nigrum & EPPO:SOLNI & $30.19(0.49)$ \\
\hline Urticaceae & Urtica dioica & EPPO:URTDI & $19.35(0.32)$ \\
\hline Zygophyllales & Tribulus terrestris & EPPO:TRBTE & $27.52(0.46)$ \\
\hline \multicolumn{4}{|c|}{ Parasitic weed species target of the allelopathic activity } \\
\hline Orobanchaceae & Orobanche crenata & ORACR & \\
\hline Orobanchaceae & Orobanche cumana & ORACE & \\
\hline Orobanchaceae & Orobanche minor & ORAMI & \\
\hline Orobanchaceae & Phelipanche ramosa & ORARA & \\
\hline
\end{tabular}

${ }^{\star}$ EPPO Code. European and Mediterranean Plant Protection Organization. https://gd.eppo.int.

weed plants at vegetative stages were removed from the pots, their roots were carefully washed in distilled water, quickly dried with filter paper, and immediately frozen and maintained at $-80^{\circ} \mathrm{C}$ until lyophilization.

Broomrape seeds were collected using a $0.6 \mathrm{~mm}$ mesh-size sieve (Filtra) from dry inflorescences of $O$. crenata infecting faba bean plants in Spain, O. cumana infecting sunflower plants in Turkey, O. minor infecting red clover in France and P. ramosa infecting oilseed rape in France, and these seeds were stored dry in the dark at $4^{\circ} \mathrm{C}$ until used.

\section{Extraction of dried roots of weed plants}

A general method was used to make extractions from the weed roots. Approximately $6 \mathrm{~g}$ of dried root tissue of each weed plant was milled in a Waring blender, and the resulting powder was extracted overnight in $\mathrm{MeOH}-\mathrm{H}_{2} \mathrm{O}(200 \mathrm{~mL}, 1: 1, \mathrm{v}: \mathrm{v})$ under stirring at room temperature in the dark. The resulting sus- pension was then centrifuged for $1 \mathrm{~h}$ at 7000 r.p.m. at $4^{\circ} \mathrm{C}$. The supernatant was then extracted with $\mathrm{CH}_{2} \mathrm{Cl}_{2}$ (three $\times 200 \mathrm{~mL}$ ). The organic extracts were combined, dried $\left(\mathrm{Na}_{2} \mathrm{SO}_{4}\right)$, filtered and evaporated under reduced pressure.

\section{Germination and radicle growth bioassays}

Allelopathic effects of the organic and the aqueous phase extracts from weed roots (Table 1) were assessed for broomrape germination and radicle growth in independent bioassays that were conducted according to previously described protocols (Fernández-Aparicio et al., 2013; Cimmino et al., 2014). Broomrape seed germination is achieved through a two-step process, including warm stratification conditioning followed by chemical stimulation (Lechat et al., 2012). For detection of stimulatory activity of germination, root extracts were dissolved in water, and water without root extracts was used as control. For the discov- 
ery of inhibitory activity of radicle growth, the root extracts were mixed with GR24 and, GR24 without root extracts was used as a control.

Seeds of the four broomrape species were surface sterilized by immersion for $5 \mathrm{~min}$ in $0.5 \%(\mathrm{w} / \mathrm{v}) \mathrm{NaOCl}$ and $0.02 \%(\mathrm{v} / \mathrm{v})$ Tween 20, and were then rinsed thoroughly with sterile distilled water, and dried in a laminar air flow cabinet. Approximately 100 seeds of each broomrape species were placed separately on $9 \mathrm{~mm}$ diameter glass fiber filter paper disks (GFFP) (Whatman International Ltd.) each moistened with $50 \mu \mathrm{L}$ of sterile distilled water and then placed in incubators at $23^{\circ} \mathrm{C}$ for $10 \mathrm{~d}$ inside Parafilm-sealed Petri dishes, to allow seed conditioning. The GFFP disks containing conditioned broomrape seeds were then each transferred onto a sterile sheet of filter paper to remove the excess of water and transferred to a new $10 \mathrm{~cm}$ diameter sterile Petri dish.

For germination induction assays, stock solutions of each root organic extract or root aqueous phase dissolved, respectively, in methanol or sterile distilled water, were mixed with sterile distilled water to equivalent concentrations of 0 (control), 10 or $100 \mu \mathrm{g}$ dry extract per $\mathrm{mL}$ of distilled water. For radicle growth assays, the stock solutions of each root organic extract or root aqueous phase were each mixed with GR24 to concentrations of 0 (control), 10 or $100 \mu \mathrm{g}$ extract per $\mathrm{mL}$ of $10^{-6} \mathrm{M}$ GR24. Triplicate aliquots of $50 \mu \mathrm{L}$ of each sample of each sample were applied to GFFP discs. Treated seeds were incubated in the dark at $23^{\circ} \mathrm{C}$ for $7 \mathrm{~d}$ and percent germination and radicle growth were determined for each GFFP disc as described by Cimmino et al. (2014) and Fernández-Aparicio et al. (2013), using a stereoscopic microscope (Leica S9i, Leica Microsystems $\mathrm{GmbH})$. Broomrape seed germination was determined by counting the number of germinated seeds from 100 seeds for each GFFP disc (Fernández-Aparicio et al., 2013). For assessing characteristics of radicle growth, the average of ten randomly selected radicles were examined (Westwood and Foy, 1999). The percentage germination induction from each treatment was then calculated relative to the average germination of control seeds (seeds treated with water), and the percentage of radicle growth inhibition for each treatment was calculated relative to the average radicle growth of control treatments (radicles treated with GR24).

\section{TLC and HPLC analysis}

Analytical and preparative Thin Layer Chromatography (TLC) of plant extracts were carried out on silica gel plates (Kieselgel 60 or $\mathrm{F}_{254}$, respectively 0.25 and 0.5 $\mathrm{mm}$ ), and on reverse phase plates (Kieselgel $60 \mathrm{RP}-18$,
$\mathrm{F}_{254}, 0.20 \mathrm{~mm}$ ) (Merck). Eluents used were: $\mathrm{CHCl}_{3}$-iso$\mathrm{PrOH}$ 9:1 v/v for direct-phase TLC and $\mathrm{MeCN}-\mathrm{H}_{2} \mathrm{O}$ $6: 4 \mathrm{v} / \mathrm{v}$ for reverse-phase TLC analysis. Spots were visualized by exposure to UV light $(254 \mathrm{~nm})$, or by first spraying with $10 \% \mathrm{H}_{2} \mathrm{SO}_{4}$ in methanol and then with $5 \%$ phosphomolybdic acid in ethanol, followed by heating at $110^{\circ} \mathrm{C}$ for $10 \mathrm{~min}$. The High Performance Liquid Chromatography (HPLC) system used for the analyses of the plant root extracts was from Hitachi, and consisted of a pump (model 5160) and a spectrophotometric UV detector (model 5410) fixed at $254 \mathrm{~nm}$. Metabolites separation was performed using a Phenomenex Luna $\mathrm{C}_{18}$ reversed-phase column $(15 \times 4.6 \mathrm{~mm} ; 5 \mu \mathrm{m}$ particle size), which was eluted at a flow rate of $0.5 \mathrm{~mL} \mathrm{~min}{ }^{-1}$. Two HPLC conditions were used. In the first, the gradient commenced from $50 \% \mathrm{MeCN}-50 \% 0.1 \% \mathrm{HCOOH}$ for $20 \mathrm{~min}$, and then linearly increased from $50 \%$ to $90 \%$ $\mathrm{MeCN}$ in $20 \mathrm{~min}$, and remained at these conditions for $10 \mathrm{~min}$. The phase was then followed by a re-equilibrium to the initial gradient composition in $10 \mathrm{~min}$. In the second, the gradient commenced from $60 \% \mathrm{MeCN}-40 \%$ $0.1 \% \mathrm{HCOOH}$ for $30 \mathrm{~min}$, and then linearly increased from $60 \%$ to $90 \% \mathrm{MeCN}$ in $20 \mathrm{~min}$, and remained at these conditions for $10 \mathrm{~min}$. The phase was then followed by a re-equilibrium to the initial gradient composition for $10 \mathrm{~min}$.

\section{Statistical analyses}

Percentage data were approximated to normal distributions and stabilize variances using angular transformations $(180 / \pi \times$ arcsine (sqrt[\%/100]). Significance of the weed species donor of activity, the targeted broomrape species and their interactions on induction of suicidal broomrape germination and inhibition of radicle growth was assessed using two-way ANOVA (SPSS version 21.0; SPSS Inc.). For each broomrape species, the significance of mean differences among donor weed species was evaluated by the least significant difference (LSD) $(P<0.05)$. Null hypotheses were rejected at the level of 0.05 .

\section{RESULTS AND DISCUSSION}

The weed root extractions yielded percentages of organic extract relative to the lyophilized root weight that ranged from $0.23 \%$ for Amaranthus albus L. to a maximum of $1.85 \%$ for Fumaria officinalis L. (Table 1). Firstly, the potential was assessed for the weed root extracts to induce broomrape suicidal germination. Germination of broomrape seeds in the absence of host roots is termed "suicidal" because the subsequent 
broomrape growth cannot reach host plants which are the sole nutritive sources for the parasitic weeds (Zwanenburg et al., 2016). All of the weed roots extracts were studied at two concentrations $(10$ or $100 \mu \mathrm{g}$ of root extract per $\mathrm{mL}$ of distilled water) for effects on seeds of the four broomrape species. In all cases, no germination was observed (data not shown) when seeds of the different broomrape species were treated with the negative controls $(0 \mu \mathrm{g}$ of root extract per $\mathrm{mL}$ of distilled water). The null germination values induced by the negative controls was expected because broomrape seed germination remains inhibited in absence of germination stimulants (Lechat et al., 2012). The synthetic strigolactone GR24 used as a positive control induced the greatest proportions of mean germination of $O$. crenata seeds, $71.3 \pm 3.1 \%$, O. cumana, $70.8 \pm 2.5 \%$, O. minor, $72.8 \pm$ $2.0 \%$, and of $P$. ramosa, $94.6 \pm 1.1 \%$.

Different protocols have been previously used for isolation of germination stimulants in plant roots. BoutetMercey et al. (2018) extracted germination stimulants from pea roots, using a method which included $2 \mathrm{~h}$ shaking at $4^{\circ} \mathrm{C}$ of ground frozen roots, and after centrifugation, the supernatant was dissolved in heptane/EtOAc followed by solid phase extraction. Yoneyama et al. (2016) used a different method, which macerated sorghum root pieces in ethanol for up to $3 \mathrm{~d}$. The efficiency of maceration and extraction methods from plant tissues depend on the cellular localization and polarity of the targeted compounds (Halouzka et al., 2020). In the present study, weed root extracts were shown to induce broomrape seed germination (Figure 1). This indicates that extraction method used here was appropriate for identification of broomrape germination stimulants in root tissues.

Germination-inducing activity of weed root extracts was studied for two host-specialist broomrape species $O$. crenata and O. cumana and two host-generalist broomrape species $O$. minor and $P$. ramosa. Germination of $O$. crenata seeds was not induced (data not shown) by root extracts from any of the weed species tested at the assessed concentrations (10 or $100 \mu \mathrm{g}$ dry extract per $\mathrm{mL}$ of distilled water). These results indicate that none of the weed root extracts have potential as sources of suicidal germination inducers for $O$. crenata-infested fields. Broomrape seed sensitivity to differing germination stimulants exuded by different crops is used a proxy of host specialization (Fernández-Aparicio et al.,
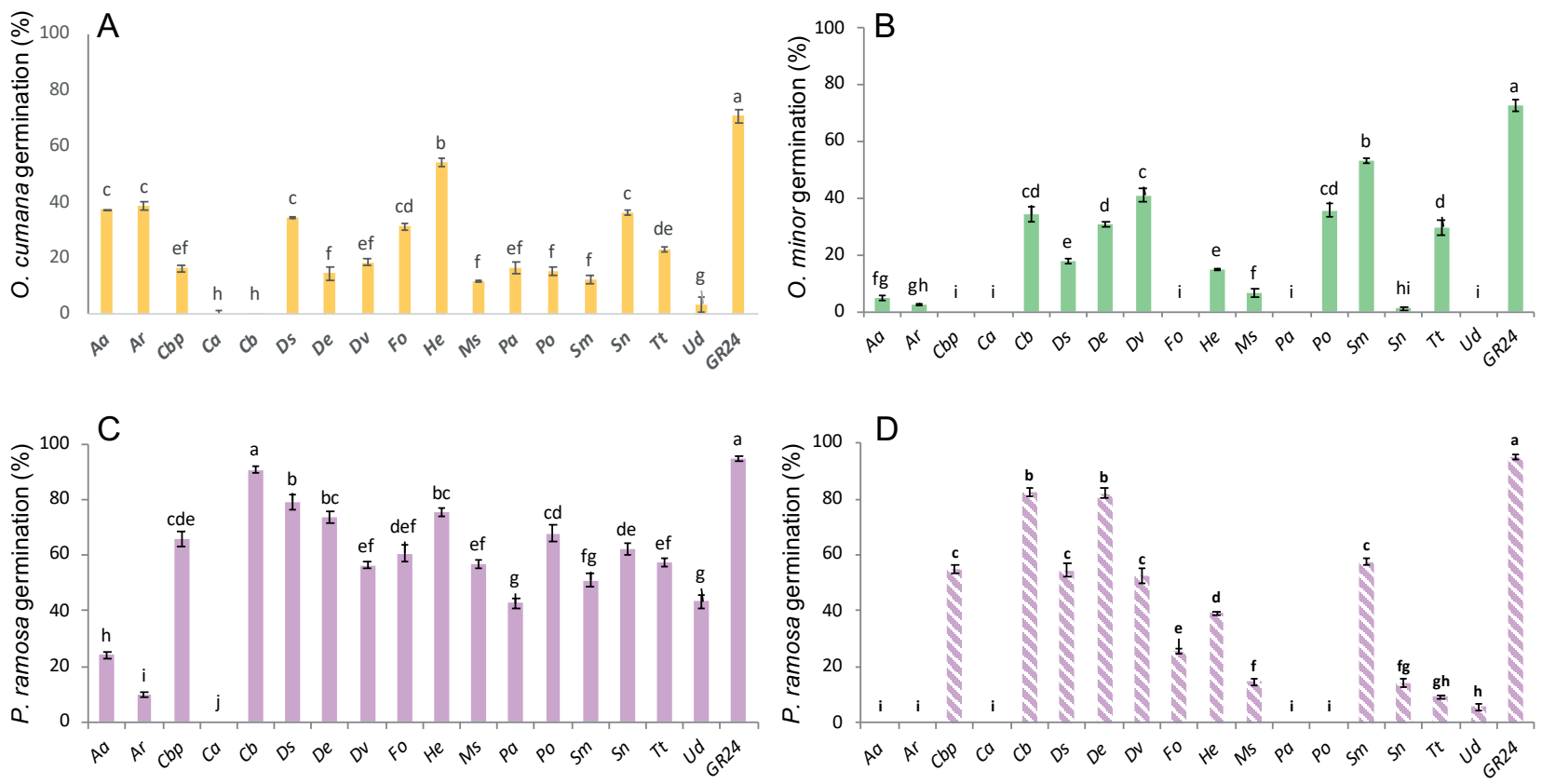

Figure 1. Mean seed germination proportions (\%) of three broomrape species induced by organic extracts from roots of seventeen weed species, including Amaranthus albus L. (Aa); Amaranthus retroflexus L. (Ar); Cbp, Capsella bursa-pastoris (L.) Medik.; Ca, Convolvulus arvensis L.; Cb, Conyza bonariensis L.; Ds, Datura stramonium L.; De, Diplotaxis erucoides (L.) DC.; Dv, Diplotaxis virgate (Cav.) DC.; Fo, Fumaria officinalis L., He, Heliotropium europaeum L.; Ms, Malva sylvestris L.; Pa, Polygonum aviculare L.; Po, Portulaca oleracea L.; Sm, Silybum marianum (L.) Gaertn., Solanum nigrum L.; Tt, Tribulus terrestris Boiss.; Ud, Urtica dioica L.. Root extracts were applied at $100 \mu \mathrm{g}$ (A-C) or $10 \mu \mathrm{g}$ (D) of root organic extract per $\mathrm{mL}$ distilled water to seeds of Orobanche cumana Wallr. (A), Orobanche minor Sm. (B) or Phelipanche ramosa (L.) Pomel. (C and D). For each broomrape species, means accompanied by different letters are significantly different according to the LSD test $(P<0.05)$. Error bars represent the standard error of the mean. 
2009; Fernández-Aparicio et al., 2011; Huet et al., 2020). Orobanche crenata has a narrow host range mainly specialized to Fabaceae and Apiaceae (Parker, 2013), and consistently with host range, its germination is induced by a narrow range of plant species and molecules when compared with other broomrape species (FernándezAparicio et al., 2009).

When weed root extracts were applied to the other three broomrape species at $100 \mu \mathrm{g}$ dry extract per $\mathrm{mL}$ distilled water (Figure 1A, B and C), significant effects were detected in the induction of suicidal germination for broomrape species target of allelopathic activity (ANOVA, $P<0.001$ ) and weed species donor of allelopathic activity (ANOVA, $P<0.001$ ). The host generalist $P$. ramosa attacks a wide range of crops in Solanaceae, Brassicaceae, Cannabaceae, Fabaceae, Apiaceae, and Asteraceae (Parker, 2013), and its parasitic life cycle is initiated by germination stimulants exuded by roots of many plant species (Fernández-Aparicio et al., 2009). Germination of $P$. ramosa was strongly induced by root extracts of most of the weed species assessed. Exceptions were A. albus and Amaranthus retroflexus L. which induced low statistically significant germination, and Convolvulus arvensis L. that did not induce germination. Consistent with the present results, root exudates of $C$. arvensis were also shown to be inactive inducers of $P$. ramosa seed germination in investigations conducted by Gibot-Leclerc et al. (2013). Despite the usual correlations observed in broomrape species between broad host range and high germination sensitivity to different root exudates and germination stimulants released by diverse crop species, these correlations were not observed in the present study for O. cumana and O. minor against stimulation of different weed root extracts. While the germination of the sunflower specialist $O$. cumana was induced by root extracts of all the plant species assessed except $C$. arvensis and Conyza bonariensis L., germination of the host generalist $O$. minor was induced by few weeds species, mainly $C$. bonariensis, Diplotaxis spp., Portulaca oleracea L., Silybum marianum (L.) Gaertn and Tribulus terrestris Boiss.

A significant interaction was detected between effects of targeted broomrape species and weed species root extracts (ANOVA, $P<0.001$ ). For example, the extracts from Heliotropium europaeum L. or Solanum nigrum L. gave high activity against seed germination of $O$. cumana and $P$. ramosa but not of $O$. minor or $O$. crenata. In contrast, C. bonariensis (Asteraceae) gave high germination induction for $P$. ramosa and $O$. minor but was not active for $O$. crenata or the sunflower specialist O. cumana. Root extracts of both species of Amaranthus induced high germination of $O$. cumana seeds but gave little or null activity for seeds of O. crenata, O. minor and $P$. ramosa. The root extract of $C$. arvensis did not induce germination for any of the broomrape species assessed. Different classes of broomrape germination stimulants have been detected in crops, and each crop species exudes a characteristic germination stimulant profile active in specific broomrape species. Specificity in recognition of different classes of germination stimulants by broomrape species has been reported (Fernández-Aparicio et al., 2008; Fernández-Aparicio et al., 2009; Xie et al., 2010; Fernández-Aparicio et al., 2014).

When weed root extracts from most of the assessed weed species were applied to seeds of $O$. cumana and $O$. minor at $10 \mu \mathrm{g}$ per $\mathrm{mL}$, activity on broomrape germination was reduced to negligible levels (data not shown). The exceptions were the extracts from $S$. marianum on germination of $O$. cumana $($ mean $=27.9 \pm 0.4 \%$ ) and $O$. minor ( $31.7 \pm 0.9 \%$ ), and for germination of O. cumana seeds which was induced by extracts from Diplotaxis virgata (Cav.) DC. (19.9 $\pm 0.8 \%)$, F. officinalis L. (14.9 $\pm 1.7 \%)$, H. europaeum (17.2 $\pm 1.0 \%)$, and Polygonum aviculare L. $(9.4 \pm 0.3 \%)$. Seeds of $P$. ramosa were more sensitive to the application of $10 \mu \mathrm{g}$ per $\mathrm{mL}$ extracts (Figure 1D), with the most active extracts were those obtained from C. bonariensis $(82.4 \pm 1.7 \%)$ and Diplotaxis erucoides (L.) DC. $(82.0 \pm 1.7 \%)$. The main classes of identified broomrape germination stimulants are strigolactones (Xie et al., 2010) biosynthetically derived from carotenoids (Matusova et al., 2005). More than 25 strigolactones have been identified in crops (Aliche et al., 2020) and their different structural conformations have species-specific activity for broomrape germination (Fernández-Aparicio et al., 2011). Strigolactones are active on parasitic weed germination at very low concentrations when tested in pure solutions (Xie, 2016; Huet et al., 2020). Other different natural substances (e.g. polyphenols, isothiocyanates, benzonitrils, saponins, and sesquiterpenes) isolated from plants species show broomrape germination stimulantion when tested at high concentrations (Cimmino et al., 2018). The unknown metabolites contained in weed root extracts responsible for the suicidal germination activity recorded in the present study gave activity in the complex mixtures of metabolites present in root extracts of each weed investigated. This could indicate significant activity strength, so these compounds will be isolated and characterized in future studies.

The germination inducing activity of aqueous phase root extracts of each weed species was also studied for seeds of O. crenata, O. cumana, O. minor, and P. ramosa at 100 or $10 \mu \mathrm{g}$ of root extract per $\mathrm{mL}$ distilled water. In most cases, no germination was observed. The exceptions were when seeds of $P$. ramosa were treated with the aqueous extracts from roots of $D$. erucoides or $D$. 
virgata. At $100 \mu \mathrm{g}$ of $D$. erucoides root extract per $\mathrm{mL}$ distilled water, mean germination of $P$. ramosa was 90.2 $\pm 0.7 \%$, and for this concentration of extract from D. virgata was $56.8 \pm 2.3 \%$. At $10 \mu \mathrm{g}$ per $\mathrm{mL}$ distilled water, extract from $D$. erucoides gave $63.6 \pm 0.3 \%$ germination of $P$. ramosa, and extract from D. virgata gave $54.6 \pm$ $2.3 \%$ germination of $P$. ramosa. Future characterization of a highly water-soluble molecule with broomrape germination activity could provide a tool for field applications to manage parasitic weeds.

In addition to the identification of potential root extracts as suicidal germination inducers, the organic and aqueous phase extracts from roots of seventeen weed species (Table 1) were also studied for their potential inhibitory activities towards broomrape radicle growth (Figures 2 and 3). All the root extracts were assessed at two concentrations (100 or $10 \mu \mathrm{g}$ of root extract /mL GR24). No inhibitory activity of radicle growth was observed in any of the aqueous phases regardless the concentration tested nor in the organic extracts applied at the lowest concentration of $10 \mu \mathrm{g}$ of root extract /mL GR24 (data not shown). At $100 \mu \mathrm{g}$, significant effects on radicle growth were detected for broomrape species target of allelopathic activity (ANOVA, $P<0.001)$ and weed species donors of allelopathic activity (ANOVA, $P<0.001$ ) and their interactions (ANOVA, $P<0.001$ ). Roots of $C$. arvensis consistently inhibited radicle growth of all the broomrape species studied (Figure 2, Figure 3A and D) in comparison with experimental controls (Figure $3 \mathrm{C}$ and $\mathrm{F}$ ). The mean radicle growth inhibition induced by $C$. arvensis was $56.9 \pm 4.7 \%$ for $O$. crenata radicles, $45.3 \pm 3.2 \%$ for $O$. cumana radicles, $57.7 \pm 1.1 \%$ for $O$. minor radicles, and $82.5 \pm 1.2 \%$ for $P$. ramosa radicles. Besides inhibition of radicle growth, $C$. arvensis root extract induced staining of $O$. crenata radicles as intense yellow with swollen root tips (Figure 3A). The yellow stain was not observed in radicles of any other broomrape species treated with root extract of C. arvensis or any other weed. Orobanche crenata radicles were not inhibited by root extracts of any other weed species. In contrast, growth of P. ramo$s a$ radicles was inhibited by most weed extracts, except
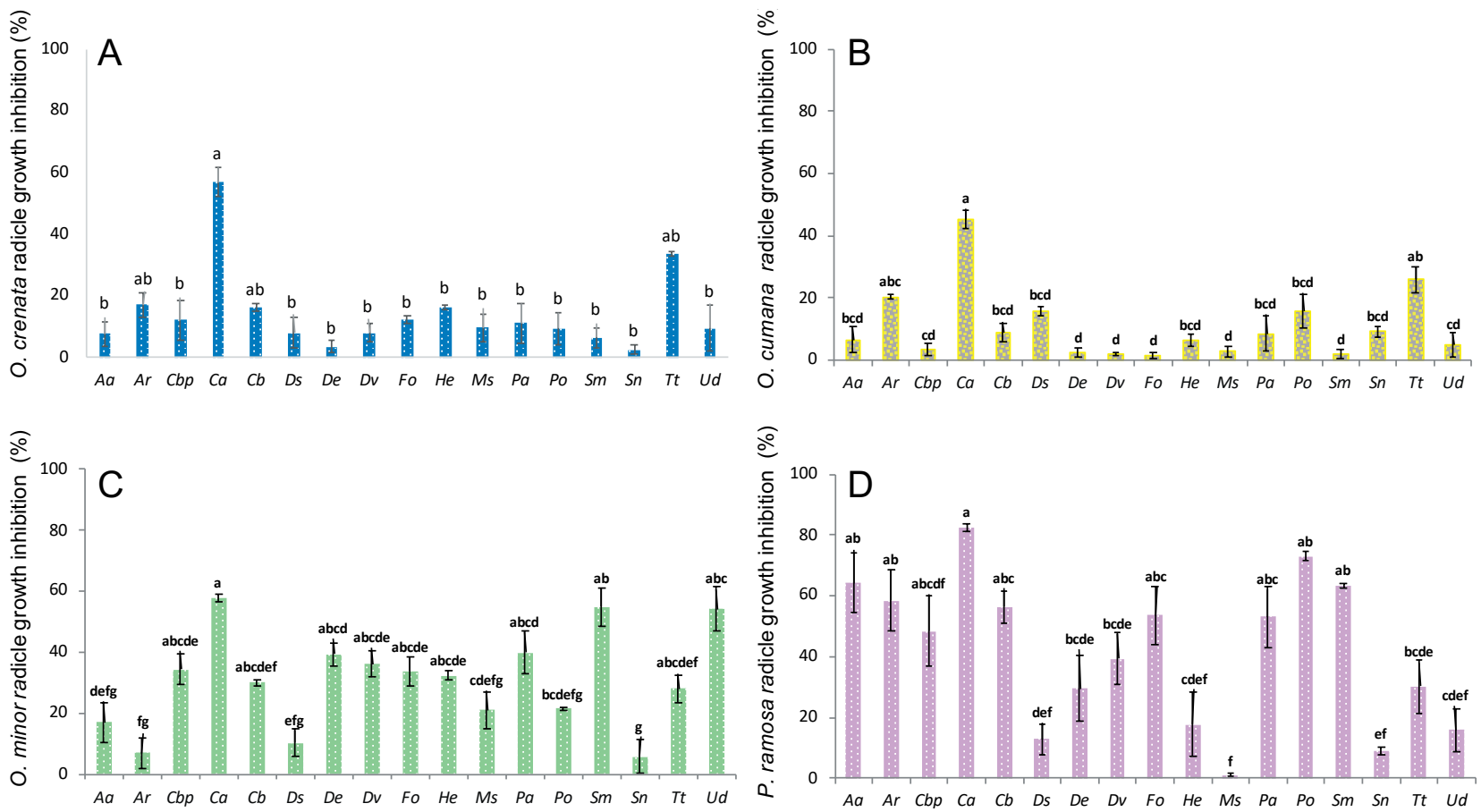

Figure 2. Mean growth inhibition of broomrape radicle growth induced by organic extracts from roots of seventeen weed species, including: Amaranthus albus L. (Aa); Amaranthus retroflexus L. (Ar); Cbp, Capsella bursa-pastoris (L.) Medik.; Ca, Convolvulus arvensis L.; Cb, Conyza bonariensis L.; Ds, Datura stramonium L.; De, Diplotaxis erucoides (L.) DC.; Dv, Diplotaxis virgate (Cav.) DC.; Fo, Fumaria officinalis L., He, Heliotropium europaeum L.; Ms, Malva sylvestris L.; Pa, Polygonum aviculare L.; Po, Portulaca oleracea L.; Sm, Silybum marianum (L.) Gaertn., Solanum nigrum L.; Tt, Tribulus terrestris Boiss.; Ud, Urtica dioica L.. Extracts were assessed at $100 \mu \mathrm{g}$ per $\mathrm{mL}$ of organic extract $\left(10^{-6} \mathrm{M}\right)$ on radicles of four broomrape species, including: Orobanche crenata Forsk. (A); Orobanche cumana Wallr. (B); Orobanche minor Sm. (C); and Phelipanche ramosa (L.) Pomel (D). Means accompanied by different letters are significantly different according to the LSD test $(P<0.05)$. Error bars represent the standard error of the mean. 


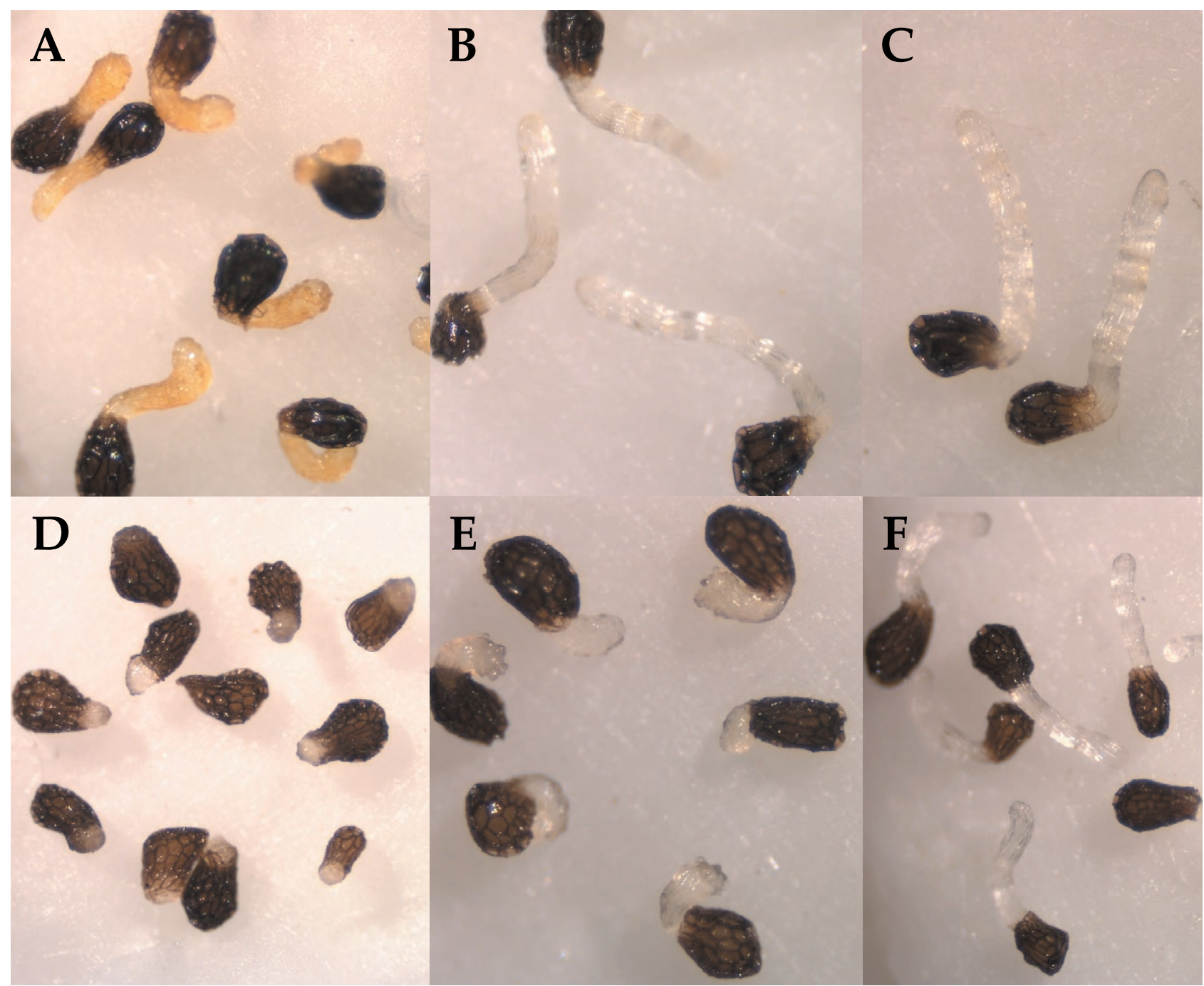

Figure 3. Photographs illustrating effects of $\mathrm{CH}_{2} \mathrm{Cl}_{2}$ organic extracts from roots of Convolvulus arvensis L. (A and D), and Portulaca oleracea L. (B and E), both compared with respective experimental controls ( $\mathrm{C}$ and $\mathrm{F}$ ) on radicle growth of (A-C) Orobanche crenata Forsk. and (D-F) Phelipanche ramosa (L.) Pomel.

those from Datura stramonium L., H. europaeum, M. sylvestris, S. nigrum L. and Urtica dioica L. Radicle growth of $O$. minor was also inhibited by most of the weed extracts, except those from A. retroflexus, D. stramonium, $M$. sylvestris, $P$. oleracea and S. nigrum. Except for $C$. arvensis, weed extracts had low inhibitory effects on O. cumana radicle growth, but low (and statistically significant) inhibitory activity was found for extracts from $A$. retroflexus, $D$. stramonium, $P$. oleracea and $T$. terrestris. The growth inhibition induced by extracts from these four weeds in O. cumana was less than $20 \%$ of the growth of control radicles.

Organic extracts were first analysed using TLC on direct (Figure $4 \mathrm{~A}$ and $\mathrm{B}$ ) and reverse phase (Figure $4 \mathrm{C}$ ) plates. Figure $4 \mathrm{~A}$ and $\mathrm{B}$ indicates that all the root extracts gave a similar mixtures of two metabolites at $\mathrm{R}_{f}=0.53$ and 0.63 when the TLC analysis was performed with $\mathrm{CHCl}_{3}$-iso-PrOH 9:1 v/v but revealed with two different methods (exposure to UV light at $254 \mathrm{~nm}$, Figure $4 \mathrm{~A}$; and by spraying first with $10 \% \mathrm{H}_{2} \mathrm{SO}_{4}$ in $\mathrm{MeOH}$, and then with 5\% phosphomolybdic acid in $\mathrm{EtOH}$, Figure 4B). However, other metabolites were present in the organic extracts from C. arvensis, S. nigrum, T. terrestris, S. marianum, P. oleracea, F. officinalis, C. bursa-pastoris and D. virgata. These results were also confirmed by the chromatographic profiles obtained using reverse phase plates eluted with $\mathrm{MeCN}-\mathrm{H}_{2} \mathrm{O}$ 6:4 v/v and spots visualized by exposure to UV light $(254 \mathrm{~nm})$ (Figure $4 \mathrm{C})$. 

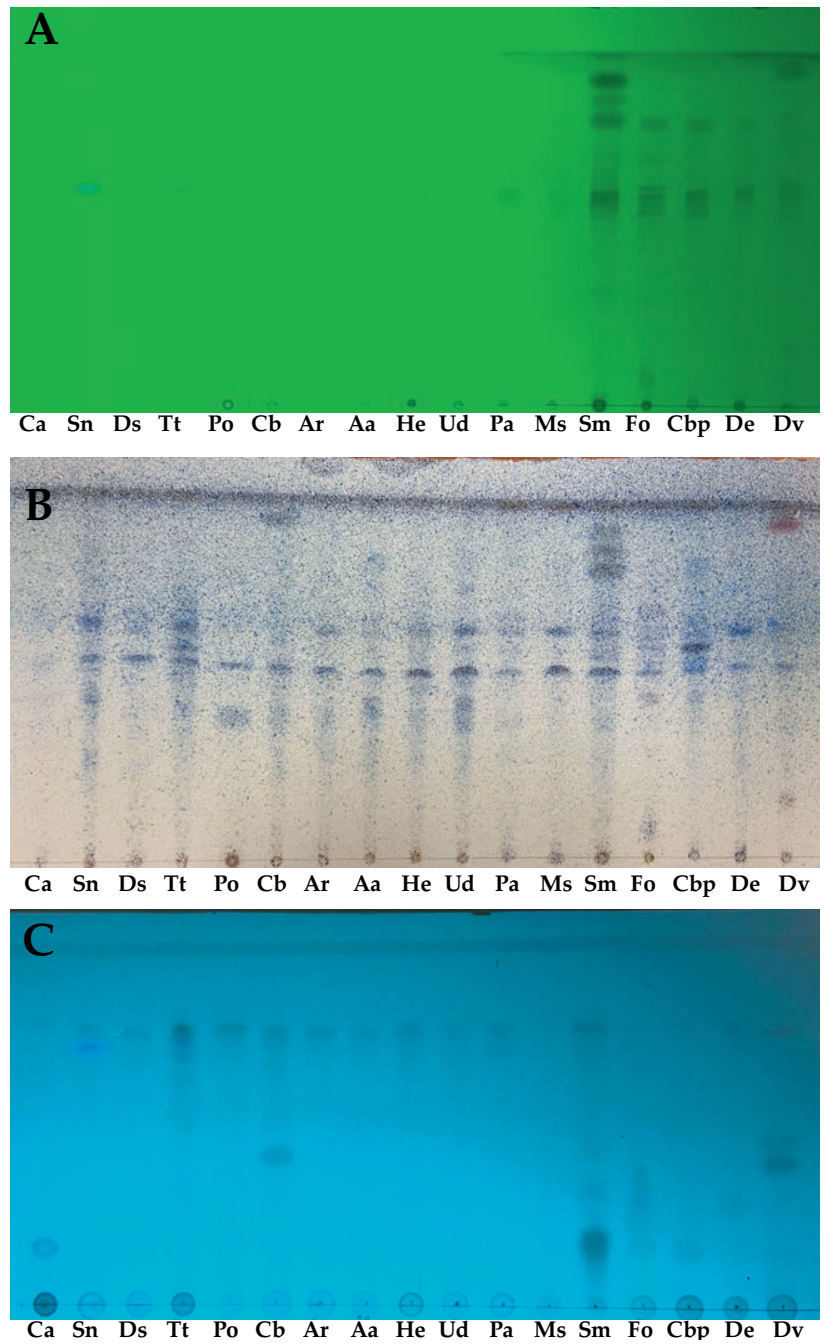

Figure 4. TLC analyses of plant root extracts from: Ca, Convolvulus arvensis L.; Sn, Solanum nigrum L.; Ds, Datura stramonium L.; Tt, Tribulus terrestris Boiss.; Po, Portulaca oleracea L.; Cb, Conyza bonariensis L.; Ar, Amaranthus retroflexus L.; Aa, Amaranthus albus L.; He, Heliotropium europaeum L.; Ud, Urtica dioica L.; Pa, Polygonum aviculare L.; Ms, Malva sylvestris L.; Sm, Silybum marianum (L.) Gaertn.; Fo, Fumaria officinalis L.; Capsella bursa-pastoris (L.) Medik.; De, D. erucoides (L.) DC. and Dv, D. virgate (Cav.) DC.. A, Chromatograms obtained using silica gel plates eluted with $\mathrm{CHCl}_{3}$ iso- $\mathrm{PrOH} 9: 1 \mathrm{v} / \mathrm{v}$ and spots visualized by exposure to UV light $(254 \mathrm{~nm}) ; \mathrm{B}$, Chromatograms obtained using silica gel plates eluted with $\mathrm{CHCl}_{3}$-iso-PrOH 9:1 v/v and visualized by spraying first with $10 \% \mathrm{H}_{2} \mathrm{SO}_{4}$ in $\mathrm{MeOH}$, and then with $5 \%$ phosphomolybdic acid in $\mathrm{EtOH}$, followed by heating at $110^{\circ} \mathrm{C}$ for $10 \mathrm{~min}$; C, Chromatogram obtained using reverse phase plates eluted with $\mathrm{MeCN}^{-\mathrm{H}_{2} \mathrm{O}} 6: 4 \mathrm{v} / \mathrm{v}$ and spots visualized by exposure to UV light $(254 \mathrm{~nm})$.

The organic extracts were also analyzed using HPLC, using the conditions designated a (see above). The optimized HPLC analyses (using the conditions designated b, above) of extracts from the active plants are reported in
Figure 5. In particular, the extracts analyzed were those of $C$. bonariensis, which gave high germination inducing activity for $P$. ramosa and $O$. minor but were not active for O. cumana or O. crenata; $H$. europaeum and $S$. nigrum which gave high seed germination induction for $O$. cumana and P. ramosa, but not for O. minor or O. crenata; $A$. albus and A. retroflexus which gave high levels of germination of $O$. cumana seeds, but low or no activity for seeds of O. crenata, O. minor or P. ramosa and root extracts of $C$. arvensis which did not induce germination in any of the broomrape species assessed.

Among these active organic extracts, the present study has identified those obtained from $C$. arvensis, C. bonariensis, $P$. oleracea, and D. euricoides for future isolation and characterization of bioactive metabolites with herbicidal activity against early stages of broomrape development, particularly focusing on the promising TLC profiles and HPLC analyses. Phytochemical analysis of these weed species components have been reported for some of the plants assessed in the present study. From C. arvenis, carbohydrates, coumarins, saponins, flavanoids, lipids, steroids, terpenoids, alkaloids, tannins and lactones have been isolated from Convolvulus (Salehi et al., 2020), while homoisoflavonoids, terpenoids, alkaloids, cerebrosides, coumarins, flavonoids and organic acids have been isolated from $P$. oleracea (Yan et al., 2012; Wang et al., 2017). Phenylpropanoids, flavonoids, sesquiterpenes, alkaloids, and phenolic acids have been isolated from $A$. retroflexus (Fiorito et al., 2017), and glycosides and monoterpenes have been isolated from C. bonariensis (Kong et al., 2001; Zahoor et al., 2010; Miranda et al., 2015). Flavonoids and their glycosides have been obtained from D. eurocoides (Salah et al., 2015; Hussein et al., 2017). Roots extract from these plants could be used combined with other broomrape management methods (e.g. crop resistance to haustorial infection, modification of crop sowing dates, fertilizer applications, biological control agents) as components of strategies for integrated broomrape management. These strategies will reduce the use of synthetic herbicide for eco-friendly weed control practices (Scavo and Mauromicale, 2020).

In conclusion, this paper is the first report of the allelopathic potential of seventeen weeds for management of Orobanche and Phelipanche species which can be responsible of heavy losses in important crops. Assessments of weed root organic extracts were carried out to characterize antagonist activity as well as corresponding chemical composition. These results are an important starting point for the isolation and characterization of metabolites with allelopathic activity against parasitic weeds. Further investigations will potentially 

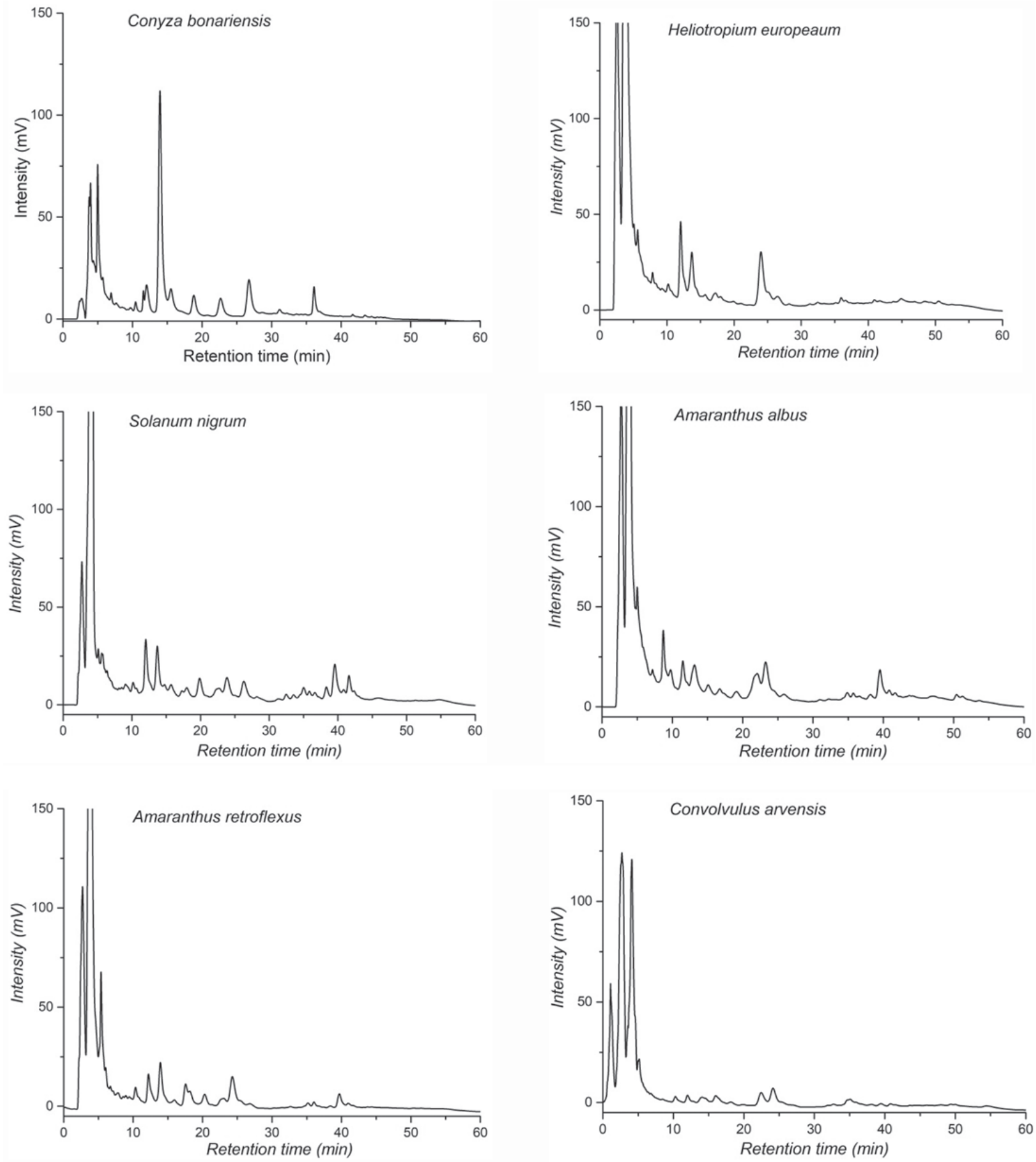

Figure 5. Optimized HPLC analysis of the extracts of the active plants: Conyza bonariensis L., Heliotropium europaeum L., Solanum nigrum L., Amaranthus albus L., Amaranthus retroflexus L. and Convolvulus arvensis L.. The HPLCs were obtained using a $0.5 \mathrm{~mL} \mathrm{~min}^{-1}$ flow rate and the gradient: commencing from $60 \% \mathrm{MeCN}-40 \% 0.1 \% \mathrm{HCOOH}$ for $30 \mathrm{~min}$, and then linearly increasing from $60 \%$ to $90 \% \mathrm{MeCN}$ in $20 \mathrm{~min}$, and remaining at these conditions for $10 \mathrm{~min}$. The phase was then followed by a re-equilibrium to the initial gradient composition for $10 \mathrm{~min}$. 
allow development of broomrape biocontrol method based on formulations containing active metabolites.

\section{ACKNOWLEDGEMENTS}

This research was funded by the Spanish Ministry of Science and Innovation (RYC-2015-18961 and AGL201787693-R) and from a CSIC-ALGOSUR research contract. Antonio Evidente is associated with the Istituto di Chimica Biomolecolare del CNR, Pozzuoli, Italy. Authors wish to thank INPS (Istituto Nazionale Previdenza Sociale) for funding a Ph.D. grant to Gabriele Soriano.

\section{LITERATURE CITED}

Aliche E.B., Screpanti C., De Mesmaeker A., Munnik T., Bouwmeester H.J., 2020. Science and application of strigolactones. New Phytologyst 227: 1001-1011.

Boutet-Mercey S., Perreau F., Roux A., Clave G., Pillot J.P., ... Boyer F.D., 2018. Validated method for strigolactone quantification by ultra high-performance liquid chromatography-electrospray ionisation tandem mass spectrometry using novel deuterium labelled standards. Phytochemical Analysis 29: 59-68.

Cimmino A., Fernández-Aparicio M., Andolfi A., Basso S., Rubiales D., Evidente, A., 2014. Effect of fungal and plant metabolites on broomrapes (Orobanche and Phelipanche spp.) seed germination and radicle growth. Journal of Agricultural and Food Chemistry 62: 10485-10492.

Cimmino A., Masi M., Evidente M., Superchi S., Evidente A., 2015. Fungal phytotoxins with potential herbicidal activity: chemical and biological characterization. Natural Product Reports 32: 1629-1653.

Cimmino A., Masi M., Rubiales D., Evidente A., FernándezAparicio M., 2018. Allelopathy for parasitic plant management. Natural Product Communications 13: 289-294.

Dayan F.E., Duke S.O., 2014. Natural compounds as nextgeneration herbicides. Plant Physiology 166: 10901105.

Duke S.O., 2012. Why have no new herbicide modes of action appeared in recent years? Pest Management Science 68: 505-512.

Eizenberg H., Hershenhorn J., Ephrath J.H., Kanampiu F. 2013. Chemical control. In Parasitic Orobanchaceae (Joel D.M., Gressel J., Musselman L.J., Eds.). Springer: Berlin/Heidelberg, Germany, pp. 415-432.

Evidente A., Cimmino A., Fernández-Aparicio M., Andolfi A., Rubiales D., Motta A., 2010. Polyphenols, including the new peapolyphenols $\mathrm{A}-\mathrm{C}$, from pea root exudates stimulate Orobanche foetida seed germination. Journal of Agricultural and Food Chemistry 58: 2902-2907.

Evidente A., Cimmino A., Fernández-Aparicio M., Rubiales D., Andolfi A., Melck D., 2011. Soyasapogenol B and trans-22-dehydrocampesterol from common vetch (Vicia sativa L.) root exudates stimulate broomrape seed germination. Pest Management Science 67: 1015-1022.

Evidente A., Fernández-Aparicio M., Cimmino A., Rubiales D., Andolfi A., Motta A., 2009. Peagol and peagoldione, two new strigolactone like metabolites isolated from pea root exudates. Tetrahedron Letters 50: 6955-6958.

Fernández-Aparicio M., Andolfi A., Evidente A., Pérezde-Luque A., Rubiales D., 2008. Fenugreek root exudates show species-specific stimulation of Orobanche seed germination. Weed Research 48: 163-168.

Fernández-Aparicio M., Cimmino A., Evidente A., Rubiales D., 2013. Inhibition of Orobanche crenata seed germination and radicle growth by allelochemicals identified in cereals. Journal of Agricultural and Food Chemistry 61: 9797-9803.

Fernández-Aparicio M., Delavault P., Timko M., 2020. Management of infection by parasitic weeds: A review. Plants 9: 1184.

Fernández-Aparicio M., Flores, F., Rubiales, D., 2009. Recognition of root exudates by seeds of broomrape (Orobanche and Phelipanche) species. Ann. Bot. 103: 423-431.

Fernández-Aparicio M., Kisugi T., Xie X., Rubiales D., Yoneyama K., 2014. Low strigolactone root exudation: A novel mechanism of broomrape (Orobanche and Phelipanche spp.) resistance available for faba bean breeding. Journal of Agricultural and Food Chemistry 62: 7063-7071.

Fernández-Aparicio M., Yoneyama K., Rubiales D., 2011. The role of strigolactones in host specificity of Orobanche and Phelipanche seed germination. Seed Science Research 21: 55-61.

Fernández-Aparicio, M., Flores F., Rubiales D., 2016. The effect of Orobanche crenata infection severity in faba bean, field pea and grass pea productivity. Frontiers in Plant Science 7: 1049.

Fiorito S., Epifano F., Palmisano R., Genovese S., Taddeo V.A., 2017. A re-investigation of the phytochemical composition of the edible herb Amaranthus retroflexus L. Journal of pharmaceutical and biomedical analysis 143: 183-187.

Gibot-Leclerc S., Abdennebi-Abdemessed N., Reibel C., Colbach N., 2013. Non-host facilitators, a new category that unexpectedly favours parasitic weeds. Agronomy for Sustainable Development 33: 787-793. 
Halouzka R., Zeljkovic S.C., Klejdus B., Tarkowski P., 2020. Analytical methods in strigolactone research. Plant Methods 16: 76.

Heap I. The International Survey of Herbicide Resistant Weeds. www. weedscience.com. Accessed: March 21, 2021.

Huet S., Pouvreau J.-B., Delage E., Delgrange S., Marais C., ... Poulin L., 2020. Populations of the parasitic plant Phelipanche ramosa influence their seed microbiota. Frontiers in Plant Science 11: 1075.

Hussein S.R., Marzouk M.M., Kassem M.E., Abdel Latif R.R., Mohammed R.S., 2017. Chemosystematic significance of flavonoids isolated from Diplotaxis acris (Brassicaceae) and related taxa. Natural Product Research 31: 347-350.

Ibn H., Tyrwhitt T., 1781. Orpheus Peri Lithôn de Lapidibus, Poema Orpheo a Quibusdam Adscriptum. Payne, White, and Elmsly, London.

International Allelopathy Society (IAS) Constitution and Bylaws 1996. [Online].

Joel D.M., 2013. Functional structure of the mature haustorium. In Parasitic Orobanchaceae; (D.M. Joel, J. Gressel, L.J. Musselman ed.) Springer, Berlin/Heidelberg, Germany, 25-60.

Kong L.D., Abliz Z., Zhou C.X., Li L.J., Cheng C.H.K., Tan R.X., 2001. Glycosides and xanthine oxidase inhibitors from Conyza bonariensis. Phytochemistry 58: 645-651.

Lechat M.M., Pouvreau J.B., Péron,T., Gauthier M., Montiel G., ... Delavault P. 2012. PrCYP707A1, an ABA catabolic gene, is a key component of Phelipanche ramosa seed germination in response to the strigolactone analogue GR24. Journal of Experimental Botany 63: 5311-5322.

Matusova R., Rani K., Verstappen F.W.A., Franssen M.C.R., Beale M.H., Bouwmeester, H.J., 2005. The strigolactone germination stimulants of the plant-parasitic Striga and Orobanche spp. are derived from the carotenoid pathway. Plant Physiologist 139: 920-934.

Miranda C.A.S.F., Carvalho M.L.M., Gomes M.S., Santiago J.A., Santiago W.D.; Teixeira M.L., 2015. Evaluation of the chemical composition and allelopathic potential of essential oils from three species of Asteraceae against seed germination and seedling vigor of lettuce Journal of Advanced Pharmaceutical Technology \& Research 11: 3669-3677.

Parker C., 2009. Observations on the current status of Orobanche and Striga problems worldwide. Pest Management Science 65: 453-459.

Parker C., 2013. The parasitic weeds of the Orobanchaceae. In Parasitic Orobanchaceae. Joel D.M., Gressel J., Musselman L.J., Eds.; Springer: Berlin/Heidelberg, Germany; pp. 313-344.
Pimentel D., Zuniga R., Morrison D. 2005. Update on the environmental and economic costs associated with alien-invasive species in the United States. Ecological Economics 52: 273-288.

Riopel J.L., Timko M.P., 1995. Haustorial initiation and differentiation. In: Parasitic Plants. (M.C. Press, J.D. Graves, ed.) Chapman \& Hall, London, UK, 39-79.

Salah N.B., Casabianca H., Jannet H.B., Chenavas S., Sanglar C., Fildier A., Bouzouita N., 2015. Phytochemical and biological investigation of two Diplotaxis species growing in Tunisia: D. virgata \& D. erucoides. Molecules 20: 18128-18143.

Salehi B., Krochmal-Marczak B., Skiba D., Patra J.K., Das S.K., Das G., Martorell M., 2020. Convolvulus plant-A comprehensive review from phytochemical composition to pharmacy. Phytotherapy Research 34: 315-328.

Scavo, A., Mauromicale, G., 2020. Integrated Weed Management in Herbaceous Field Crops. Agronomy 10(4): 466. https://doi.org/10.3390/agronomy10040466

Vurro M., Boari A., Evidente A., Andolfi A., Zermane N., 2009. Natural metabolites for parasitic weed management. Pest Management Science 65: 566-571.

Wang H., Zhang L., Wang Y., 2017. Isolating and identifying organic acids from Portulaca oleracea and determining their anti-cyanobacterial activity. Polish Journal of Environmental Studies 26: 441-445.

Westwood J.H., Charudattan R., Duke S.O., Fennimore S.A., Marrone P., ... Swanton C., Zollinger R., 2018. Weed Management in 2050: Perspectives on the Future of Weed Science. Weed Science, 10.1017/ wsc. 2017.78 .

Westwood, J.H., Foy, C.L. 1999. Influence of nitrogen on germination and early development of broomrape (Orobanche spp.). Weed Science 47: 2-7.

Xie X., 2016. Structural diversity of strigolactones and their distribution in the plant kingdom. Journal of Pesticide Science 41: 175-180.

Xie X., Yoneyama K., Yoneyama K., 2010. The strigolactone story. Annual Review of Phytopathology 48: 93-117.

Yan J., Sun L.R., Zhou Z.Y., Chen Y.C., Zhang W.M., Dai H.F., Tan J.W., 2012. Homoisoflavonoids from the medicinal plant Portulaca oleracea. Phytochemistry 80: $37-41$.

Yoneyama K., Xie X., Nomura T., Yoneyama K., 2016. Extraction and measurement of strigolactones in sorghum roots. Bio-protocol 6: e1763.

Zahoor A., Siddiqui I.N., Khan A., Ahmad V.U., Ahmed A., Hassan Z., Iqbal, S. 2010. Two new glycosides from Conyza bonariensis. Natural Product Communications 5: 1099-1102.

Zwanenburg B., Mwakaboko A.S., Kannan C., 2016. Suicidal germination for parasitic weed control. Pest Management Science 72: 2016-2025. 